\title{
Lifting Scheme Combined with SPIHT Color Image Compression Algorithm
}

\author{
Xinwen Bi \\ Institute of Information Technology and Media, Beihua University, Jilin City, China \\ 52600613@qq.com
}

\section{Keywords: MRCT; SPIHT; Lossless Compression}

\begin{abstract}
The embedded zero tree wavelet coding algorithm in wavelet transform domain is the efficient image compression coding algorithm, the wavelet transform coefficients according to their order of importance to, realize the progressive image coding, based on aggregation and $\mathrm{S}$ transform and MRCT transform in the lossless compression algorithm for image, through the simulation experiment, the JP2 respectively, RAR, ZIP, PNG, TGA, PCX, TIF lossless compression results improved an average of $2 \%, 15 \%, 51 \%, 51 \%, 34 \%, 52 \%, 31 \%$.
\end{abstract}

\section{Introduction}

The SPIHT algorithm ${ }^{[1]}$ is based on the embedded zerotree wavelet algorithm ${ }^{[2]}$ it inherits the EZW method using the correlation between the corresponding position coefficients ${ }^{[4]}$ in different frequency bands ${ }^{[3]}$ after wavelet transform, Easy to control the compression ratio ${ }^{[5]}$ and achieve scalable coding ${ }^{[6-7]}$, Greatly optimizing the location information ${ }^{[8]}$ encoding. However, the singularity of the compression coding can not be completely redundant, under this condition, a variety of algorithms combined with coding technology to achieve the redundancy of the compression technology, in this paper, we study the image compression algorithm of S-transform and SPIHT algorithm, compression results have been improved.

\section{SPIHT Algorithms}

SPIHT Algorithm Specific Symbols. $O(i, j)$ indicates the node ${ }^{(i, j)}$ a collection of all child coordinates.

$$
O(i, j)=\{(2 i, 2 j),(2 i, 2 j+1),(2 i+1,2 j),(2 i+1,2 j+1)\} \text { 。 }
$$

$D(i, j)$ represents the set of all the descendant coordinates of node $(i, j)$.

$\mathrm{H}$ denotes the set of transform coefficients of the largest scale of wavelet transform, both $\mathrm{LL}_{\mathrm{J}}$, $\mathrm{HL}_{\mathrm{J}}, \mathrm{LH}_{\mathrm{J}}$ and $\mathrm{HH}_{\mathrm{J}}$.

$$
L(i, j)_{\text {means }} L(i, j)=D(i, j)-O(i, j) \text { 。 }
$$

Three lists:

(LIS), important pixel list (LIP), important pixel list (LSP), in LSP,LIP, ${ }^{(i, j)}$ represents a single pixel, in LIS, $(i, j)$ represents set $L(i, j)$ or $D(i, j)$. In order to distinguish between the two types of collections, if it is $D(i, j)$ said LIS table value for the A type, if it is $L(i, j)$ said LIS table value for the B type.

SPIHT Specific Implementation Process. I Initialization:

$$
\text { Output } \mathrm{n}=\left\lfloor\log _{2}\left(\max (\mathrm{i}, \mathrm{j})\left\{\left|\mathrm{C}_{\mathrm{i}}, \mathrm{j}\right|\right\}\right\rfloor \text {, set the LSP is empty, the coordinate }(i, j) \in \mathrm{H}\right. \text { into the LIP, }
$$
and $\mathrm{H}$ in the descendants (high frequency part: HLJ,LHJ,HHJ) into the LIS, as the A value. 


\section{Sorting process:}

(1) for each $(i, j) \in$ LIP

1) Output $S_{n}(i, j)$;

2) If $S_{n}(i, j)=1$, move $S_{n}(i, j)=1$ into the LSP and output the sign of $\mathcal{C}_{(i, j)}$;

(2) for each $(i, j) \in$ LIS

1) If the value of $A$, then

(1) output $S_{n}(D(i, j))$;

(2) if $S_{n}(D(i, j))=1$, then for each $(k, l) \in O(i, j)$, as:

- Output $S_{n}(k, l)$;

- If $S_{n}(k, l)=1$, send $(\mathrm{k}, 1)$ to the LSP and output its symbol;

- If $S_{n}(k, l)=0$, send $(\mathrm{k}, \mathrm{l})$ to the end of the LIP;

(3) If $L(i, j) \neq \phi$, move $(\mathrm{k}, \mathrm{l})$ to the end of the LIS as the B value; otherwise, remove (i, j) from the LIS.

2) If the value of $B$, then

(1) output $S_{n}(L(i, j))$;

(2) if $S_{n}(L(i, j))=1$, then

- for each $(k, l) \in O(i, j)$ added to the end of the LIS as an A value;

- Delete $(i, j)$ from LIS.

(3) refinement process: for each $(i, j) \in L S P$ (not including the last splitting process), output the nth most significant bit of $\left|c_{i, j}\right|$;

(4) quantization step size refresh: $n=n-1$; return (2).

\section{S Transform}

The simplest, most generally reversible integer to integer mapping is the $\mathrm{S}$ transform, the $\mathrm{S}$ transform is well known as a reversible integer to integer transform, and its basic component is the Haar wavelet transform.

It can be expressed as:

$$
\left[\begin{array}{l}
y_{0} \\
y_{1}
\end{array}\right]=\left[\begin{array}{l}
\left\lfloor\frac{1}{2}\left(x_{0}+x_{1}\right)\right. \\
x_{0}-x_{1}
\end{array}\right]
$$

When $\left[\begin{array}{l}x_{0} \\ x_{1}\end{array}\right]=\left[\begin{array}{l}t \\ t-y_{1}\end{array}\right]$ is: $\mathrm{t} \cong y_{0}+\left\lfloor\frac{1}{2}\left(y_{1}+1\right)\right\rfloor$

Of course, the above formula is the most basic form of $\mathrm{S}$ transform, we often use more complex three-dimensional form, S-transform can be extended to the generalized S-transform generalized S-transform (GST).

Here we set $\mathrm{x}$, $\mathrm{y}$ are: 


$$
\begin{aligned}
& x \cong\left\lfloor_{X} \begin{array}{lllll}
X_{0} & X_{1} & \cdots & X_{N-1}
\end{array}\right. \\
& y \cong\left[\begin{array}{lllll}
y_{0} & y_{1} & \ldots & y_{N-1}
\end{array}\right] T
\end{aligned}
$$

There are $\mathrm{y}=\mathrm{Cx}+\mathrm{Q}((\mathrm{B}-\mathrm{I}) \mathrm{Cx})$ where $\mathrm{B}$ and $\mathrm{C}$ are what? It can be expressed as:

$$
\begin{aligned}
& \mathrm{B}=\left(\begin{array}{ccccc}
1 & \mathrm{~b}_{1} & \mathrm{~b}_{2} & \ldots & \mathrm{b}_{\mathrm{N}-1} \\
0 & 1 & 0 & \ldots & 0 \\
0 & 0 & 1 & \ldots & 0 \\
\ldots & \ldots & \ldots & \ldots \\
0 & 0 & 0 & \ldots & 1
\end{array}\right) \\
& \mathrm{C} \cong\left(\begin{array}{ccccc}
\mathrm{C}_{0,0} & \mathrm{C}_{0,0} & \mathrm{C}_{0,0} & \ldots & \mathrm{C}_{0, \mathrm{~N}-1} \\
\mathrm{C}_{1,0} & \mathrm{C}_{1,1} & \mathrm{C}_{1,2} & \ldots & \mathrm{C}_{1, \mathrm{~N}-1} \\
\mathrm{C}_{2,0} & \mathrm{C}_{2,1} & \mathrm{C}_{2,2} & \ldots & \mathrm{C}_{2, \mathrm{~N}-1} \\
& \ldots \ldots \ldots \ldots \ldots \ldots \ldots \ldots & \\
\mathrm{C}_{\mathrm{N}-1,0} & \mathrm{C}_{\mathrm{N}-1,1} & \mathrm{C}_{\mathrm{N}-1,2} & \cdots & \mathrm{C}_{\mathrm{N}-1, \mathrm{~N}-1}
\end{array}\right)
\end{aligned}
$$

Here, if $\mathrm{A} \cong \mathrm{BC}$ then $\mathrm{x}=\mathrm{C}-1(\mathrm{y}-\mathrm{Q}((\mathrm{B}-\mathrm{I}) \mathrm{y}))$. It should be noted that $\mathrm{C}-1$ is also an integer matrix. Then we look at the matrix $B$, or it can be replaced by any two unknown variables $u, v: V=u+Q$ $((B-I) \mathrm{u})$ or $\mathrm{u}=\mathrm{v}-\mathrm{Q}((\mathrm{B}-\mathrm{I}) \mathrm{v})$. Equivalent to us into $\mathrm{u}=\mathrm{Cx}$ and $\mathrm{v}=\mathrm{y}$.

$\mathrm{A}=\mathrm{BC}$, then $\mathrm{A}$ can be defined as

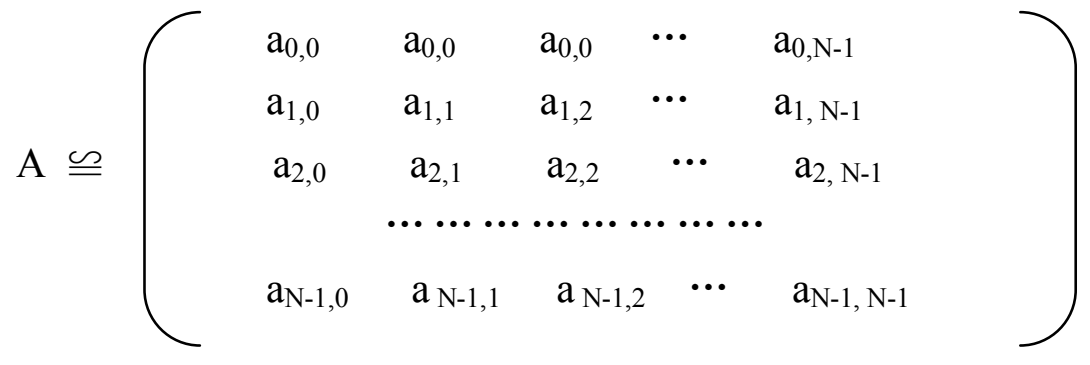

Break down the steps:

Step1. The integer term of A for N-1 rows is:

$A i, j \in Z(i=1,2, \ldots, N-1, j=0,1, \ldots, N-1)$

Step 2. The modulus of $A$ is 1 .

Step 3. $\{$ Det minor $(A, 0, i)\} N-1$ is a quality.

MRCT Transformation. When compressing a color image, the color is expressed as multiple components often in order to improve the coding efficiency. This transformation can be expressed by brightness. In this way, people can easily extract the gray scale of the image. For RGB color images, the brightness is the color of the element, it can usually be expressed as $y=0.299 \mathrm{r}+0.587 \mathrm{~g}$ $+0.114 \mathrm{~b}$ We use this formula to express the brightness and gray value when you can use this formula: $y=\frac{1}{4} r+\frac{1}{2} g+\frac{1}{4} b$

In this way the calculation is rough, there will be a lot of data loss in practical applications, if the structure of such changes can improve the approximate brightness, we call this method for the MRCT. Extended to GST as follows: 


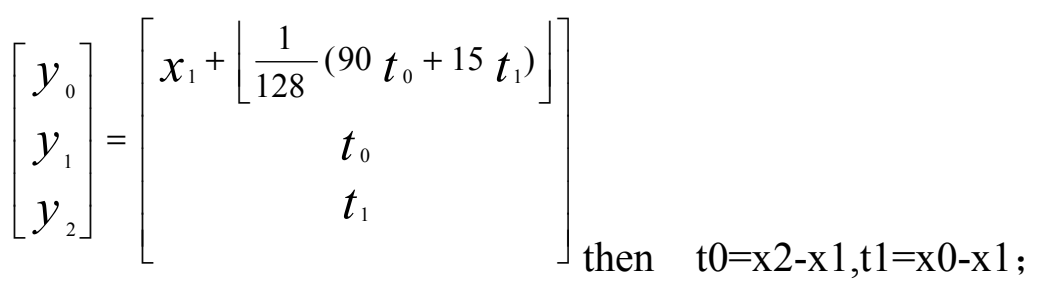

$$
\left.\left[\begin{array}{l}
x_{0} \\
x_{1} \\
x_{2}
\end{array}\right]=\left[\begin{array}{c}
s_{0} \\
s_{1} \\
s_{1}+y_{2}
\end{array}\right]_{\text {then }} \quad \mathrm{s}=\mathrm{y} 0-_{128}\left\lfloor\frac{1}{128} y_{1}+15 y_{2}\right)\right\rfloor_{\mathrm{s} 0=\mathrm{s} 2-\mathrm{y} 1}
$$

\section{Experimental Results and Conclusions}

In order to illustrate the effectiveness of the algorithm, this paper compares the lossless image compression algorithms of JP2, RAR, ZIP, PNG, TGA, PCX and TIF in 12 color international standard test images, and on average, no compression ratio Than the above algorithm were increased by $2 \%, 15 \%, 51 \%, 51 \%, 34 \%, 52 \%, 31 \%$, as shown in Table 1 .

Table 112 color international standard test image compression experiment comparison results

\begin{tabular}{|c|c|c|c|c|c|c|c|}
\hline $\begin{array}{l}\text { Compression } \\
\text { schence }\end{array}$ & JP2 & RAR & PCX & TGA & ZIP & TIF & PNG \\
$\begin{array}{l}\text { InternaTional } \\
\text { Standard } \\
\text { Test Images }\end{array}$ & & & & & & & \\
\hline Kodak1 & 511631 & 598789 & 1161410 & 1157891 & 796111 & 1065614 & 783060 \\
\hline Kodak2 & 451678 & 508771 & 1142233 & 1150300 & 665774 & 865916 & 621478 \\
\hline Kodak3 & 399015 & 458212 & 1096862 & 1085783 & 569796 & 890712 & 549676 \\
\hline Kodak4 & 461292 & 512279 & 1172752 & 1153733 & 747996 & 108740 & 640877 \\
\hline Kodak5 & 533178 & 684773 & 1185005 & 1162343 & 915984 & 1238244 & 810363 \\
\hline Kodak6 & 472736 & 532397 & 1188493 & 1148689 & 718077 & 1001630 & 673733 \\
\hline Kodak7 & 419224 & 488048 & 1113169 & 1109121 & 650774 & 976216 & 573980 \\
\hline Kodak8 & 548967 & 804423 & 1309333 & 1163564 & 951692 & 1255784 & 791697 \\
\hline Kodak9 & 446250 & 488367 & 1190110 & 1152950 & 619045 & 838012 & 587850 \\
\hline Kodak10 & 454440 & 495213 & 1171219 & 1154093 & 686399 & 958320 & 598508 \\
\hline Kodak11 & 458044 & 553611 & 1139853 & 1129959 & 699897 & 930316 & 643047 \\
\hline Kodak12 & 426781 & 482724 & 1247133 & 1130272 & 598262 & 881932 & 575313 \\
\hline SPIHT+MRCT & $2 \%$ & $15 \%$ & $51 \%$ & $51 \%$ & $34 \%$ & $52 \%$ & $31 \%$ \\
\hline
\end{tabular}

\section{Acknowledgements}

This work was financially supported by National Ministry of Education Chunhui Plan(104900071, 1049000150), Exploring Practice of C Language Program Design" Case Teaching for Professional Application (XJQN2016035).

\section{References}

[1] Tasai M J, Villasenor T D, Chen F. Stack-run image coding[J].IEEE Transactions on Circuits System Video Technology, 1996,6(5): 519-521.

[2] Mallat S. Multifrequency channel decompositions of images and wavelet models[J].IEEE 
Transactions on ASSP,1989,37(12): 2091-2109.

[3] Moffat A. Linear time adaptive coding [J].IEEE Transactions on Info Theory,1990,36(2): 401-406.

[4] Shapiro J M. Embedded image coding using zerotree of wavelet coefficients [J].IEEE Transactions on Signal Processing, 1993, 41 (12): 3445-3462.

[5] Ordentlich E, Weinberger M, Seroussi G. On modeling and ordering for embedded image coding[C]//Proc IEEE Int Symp Information Theory,2000: 297-299.

[6] Taubman D. High performance scalable image compression with EBCOT [J].IEEE Transactions on Image Processing, 2000, 9 (6): 1158-1170.

[7] Said A, Pearlman W A.A new fast and efficient image codec based on set partitioning in hierarchical trees[J].IEEE Transactions on Circuit and Systems for Video Technology, 1996, 6(3): 243-249.

[8] Witten I H, Neal R M,Clew J G. Arithmetic coding for data compression[J]. Commun ACM, 1987, 30(6): 520-540. 